\title{
Universal Design of ICT for Emergency Management from Stakeholders' Perspective
}

\section{A Systematic Literature Review}

\author{
Terje Gjøsæter ${ }^{1,2}$ (D) Jaziar Radianti $^{1} \cdot$ Weiqin Chen $^{2}$
}

Accepted: 22 October 2020 / Published online: 6 November 2020

(C) The Author(s) 2020

\begin{abstract}
While Universal Design principles have been adopted in many areas to ensure that products and services are usable for the broadest possible diversity of users, there is still an open area when it comes to the emergency management domain. This article aims at providing a systematic overview of the current state of the emerging research field of Universal Design of Information and Communication Technology (ICT) for Emergency Management, and to highlight high-impact research opportunities to ensure that the increasing introduction of ICT in Emergency Management can contribute to removing barriers instead of adding more barriers, in particular for the elderly and people with disabilities. A systematic review on relevant literature on Universal Design, ICT and Emergency Management between 2008 and 2020 was employed using predefined frameworks, to answer the following questions: (1) Who are the target audiences (stakeholders) in research on Universal Design of ICT in Emergency Management in the different categories of Emergency Management ICT tools, and to what degree is Human-Centred Design and Universal Design taken into account? (2) What are the most important challenges and gaps in research on Universal Design of ICT in Emergency Management? We identify a set of gaps in the literature, indicating that there are some challenges where Universal Design is still limitedly addressed in technology development. We also derive promising future research topics based on areas that are missing in the literature.
\end{abstract}

Keywords Universal Design of ICT $\cdot$ Human-Centred Design $\cdot$ Accessibility $\cdot$ Emergency Management

\section{Introduction}

Universal Design (UD) concerns the design of products and environments to be usable by all people, to the greatest extent possible, without the need for adaptation or specialized design. A prerequisite for Universal Design is accessibility. According to WAI/W3C, for the web, accessibility means that people with disabilities can perceive, understand, navigate, and interact with websites and tools, and that they can

Terje Gjøsæter

terjeg@uia.no

Jaziar Radianti

jaziar.radianti@uia.no

Weiqin Chen

weiche@oslomet.no

CIEM, University of Agder, Kristiansand, Norway

2 Oslo Metropolitan University, Oslo, Norway contribute equally without barriers (Bennett et al. 2017). In other words, accessibility and usability for the broadest possible diversity of users.

Universal Design in Emergency Management has until now primarily been a research field where the focus has been on the physical environment, buildings and escape routes. However, Universal Design of Information and Communication Technology (ICT) in Emergency Management and crisis communication can also greatly impact the ability to save people's life in a disaster situation. Practitioners as well as scientists agree that appropriate ICT technology can improve all parts of the disaster management and crisis communication cycle regarding the needs of people with disabilities (Bennett et al. 2017). However, research shows that Universal Design of ICT in an Emergency Management context may not only be important for people with disabilities among the general public, but a wide range of stakeholders that may also be affected by so-called situational disabilities, i.e. social and environmental barriers that can occur in the situation that cause auditory, cognitive, physical speech and visual impairment (Gjøsæter et al. 2019, 2020). The 
general public as well as diverse stakeholders such as first responders, volunteers, control room personnel, decision makers as well as representatives for government agencies and nongovernment organisations may be affected by these situational abilities, affecting senses and cognitive abilities. For example, while noise and smoke can temporarily reduce the hearing and vision among affected public and first responders, cognitive overload may also affect control room personnel and decision makers.

Research indicates that the focus on Universal Design in design of tools and platforms for use in Emergency Management has not been strong enough. To mention two examples: A selection of web-based tools and platforms for crowdsourcing of information for enhanced public resilience were examined. The results show that none of the tested tools were universally designed and accessible to all users (Radianti et al. 2017). A study of a set of emergency alert sign-up pages in the northeast of US showed that of 26 webpages that were evaluated, 21 had accessibility issues (Wentz et al. 2014). Human-Centred Design (HCD $)^{1}$ is a suitable design method to ensure that the needs and requirements of a broad diversity of users are taken into account (ISO 2019). To get a more complete overview of the situation concerning Universal Design of ICT for Emergency Management and to highlight future directions for research in this area, the following research questions are proposed:

1. Who are the target audiences (stakeholders) in research on Universal Design of ICT in Emergency Management in the different categories of Emergency Management ICT tools, and to what degree is Human-Centred Design and Universal Design taken into account?

2. What are the most important challenges and gaps in research on Universal Design of ICT in Emergency Management?

The rest of the article is organized as follows: Section 2 presents the framework that forms the basis of the systematic literature review. Section 3 presents the methodology used, and Section 4 provides the results and 5 covers key findings and gaps. Section 6 discusses the potential impact of research on different aspects of Emergency Management and proposes future research directions in this area, and finally Section 7 concludes this study.

\section{Framework for Analysis}

To better understand the knowledge status and current research on Universal Design and Emergency Management, we need a solid framework to analyse the literature, that

\footnotetext{
${ }^{1} \mathrm{HCD}$ is used in this paper as a broader term for methods involving stakeholders in the design process such as User Centered Design (UCD) and participatory design.
}

highlights the issues related to the interaction between people and tools in different situations, and development of such tools. In the following, we will suggest categories for analysis in four different aspects; Stakeholders, Categories of tools, Degree of Universal Design focus and Methods used. In the following, we will use these as the main frameworks to classify tools and technologies in the impact analysis as well as for the prioritization of the items in the research agenda.

\subsection{Stakeholders}

The primary focus for analysis is on stakeholders, i.e. both active and passive actors affected by disasters and thus is becoming target audiences of this research. Understanding of the stakeholders addressed by different technologies are important because they have different needs, different ways of interacting with the ICT technologies, and different environmental challenges. For example, it would be a different environment between those who work in the field and in the command and control room. Although they may experience a kind of stress, the sources can stem from different reasons (e.g. physical threats in the field vs. technology complexities in the command and control room). The Stakeholder categories selected for this study include:

- First Responders, are trained people and organizations who provide assistance on scene immediately when an event/ disaster occurs, for example Search and Rescue teams, police, fire personnel, health personnel, civil defence, etc. Their main needs for ICT support are vary, for instance, to get an overview of the threat development, the location of an event, the affected zones, to communicate with multiple agencies, to get overview of available resources, and resource needs and so on.

- Volunteers, are those who provide assistance in a sporadic and systematic way to support the response efforts, but do not belong to the formal emergency responders. They can be digital as well as physical volunteers, operating for onsite and remote volunteers. Their main needs can include ICT tools to coordinate the physical and digital volunteer efforts, to see the overview of the available volunteer resources and mobilize them, for systematizing the digital volunteer efforts and present the result in a meaningful way.

- Control Room Personnel, are those in charge of observing, comparing, putting together and interpreting data and disseminating information regarding disasters to decision makers. They may deal with complex ICT technologies, which can be web-based reports, communication technologies, mobile technologies and so on to enable them to get crisis overview and share them quickly to relevant stakeholders. Thus, their needs should be a simple but easy to use ICT support tools, 
- Decision Makers - Responsible for allocation of resources, logistics etc.

- Government Agencies - Civil defence, police, fire department, health services,

- NGOs - Red Cross, Doctors Without Borders,

- Experts - are those who are very knowledgeable about or skilful in the disaster and emergency management areas. They can be the scientists, designers, developers of ICT technologies,

- The Public - are all citizens that are affected or in danger of being affected by the disasters. They can be either the general public or particular members or groups of the public.

\subsection{Categories}

Aman et al. (2012) examined the use of ICT in Emergency Management, and have defined the following categories where ICT technologies are used:

- Communication - Technologies for communication among first-responders, or other responder organizations, victims and the public. It includes information creation, dissemination and validation.

- Event Detection and Assessment - Technologies used for disaster prevention, early response and damage mitigation.

- Warning - Technologies used to alert the public of potential dangers.

- GIS Support - Technologies for map-based collaboration, where the map technologies are used for responding such as map-based information sharing, obtaining common operational pictures, location sharing, map-based damage assessment, indicating disaster-affected zones, or tracking deployed resources. tracking.

- Decision Support - Technologies developed to aid in decision making. It can be an intelligent system, data analytics, recommendation system for actionable information or real-time disaster overview and prediction.

- Training - Tools used in training of first responders for emergency response activities.

- Navigation - Technologies that assist in navigating to/ from affected areas.

- Evacuation - Technologies used to assist in evacuating affected areas or areas under risk.

\subsection{Degree of Universal Design}

Universal Design of ICT seeks to ensure that ICT tools are usable and accessible to the widest range of people. We examine the degree of Universal Design focus expressed in the paper, indicated as:
- Implicit UD - A study that contains some indications of the awareness of accessibility and diversity of users, but it is not explicitly discussed.

- Brief mention of UD - A study that mentions Universal Design, accessibility or requirements of persons disabilities in passing, but without clear signs that it has been taken into account.

- Explicit UD discussion - A study that discusses Universal Design at some length, and obviously takes it into account.

- UD main topic - A study that focuses primarily on Universal Design.

\subsection{Universal Design Methods}

Universal Design is most achievable through integrating closely with solid development methodologies. In general, an Human-Centred Design ${ }^{2}$ approach is required to prioritise the requirements of diverse user groups. This approach, in the context of Universal Design of ICT, involves iterations of requirements, prototyping, and testing with different methods such as User-Centred Design (UCD)/participatory design. The following methods are identified in the collected papers:

- UCD/participatory design: A study that employs and discusses the use of user centred or participatory design in implementation of tools and technologies in EM.

- Review/case study: A study that conducts a review or case study on specific ICT tools or technologies while taking into account the universal design perspective in the research design.

- Prototypes: A study that describes the design and development of a prototype or studies the prototype itself.

- Proposals: A study that proposes the design and development of a tool or technology, or a novel approach to universal design of ICT for Emergency Management.

- Automatic testing: A study that uses automatic testing for universal design such as using automatic tools to identify barriers in the websites dedicated for emergency management.

- Heuristic testing: A study that adopts a heuristic method for testing a tool or technology, i.e. it involves the expert judgement and following a systematic procedure of evaluation.

- User testing: A study that involved users in testing a tool or technology, for accessibility and/or usability.

- Field testing: A study that tests an existing or developed tool or technology for emergency management in the field.

\footnotetext{
2 As mentioned in the Introduction, HCD is used in this paper as a broader term for methods involving stakeholders in the design process such as User Centred Design (UCD) and participatory design.
} 


\section{Method}

To better understand the status of art research in Universal Design of ICT for Emergency Management, we have conducted a systematic literature review in this emerging research field, following the PRISMA method (Panic et al. 2013) as seen in Fig. 1. As we conducted two stages review process, we modified slightly the PRISMA diagram to better capture the process we have gone through, which is divided into 4 main stages. The adaptation is mainly related to the updating stage of the paper review process conducted in 2018 (Gjøsæter et al. 2018) and newly added reviews, 2020.

First, the Identification step, we define the review scope and research questions. Based on the research questions, we have identified three topic groups to cover in the literature search:

- Universal Design, covering Universal Design, design for all, and accessibility

- Emergency Management covering crisis management, Emergency Management, disaster management, disaster resilience

- ICT covering Web, technology, digital, mobile, smartphone, computer, internet.
Before conducting the literature search, we defined the following inclusion and exclusion criteria:

- Papers must cover the three topic groups

- Papers must be peer-reviewed scientific journal and conference articles

- Paper must be in English

- Literature review papers are excluded

- Papers published after 2008 are included

We chose semanticscholar.com as our search database for practical reasons as we conducted a complex query that not all databases were able to handle correctly, and because of the large number of false positives, a good workflow for screening was needed. In addition, Semantic Scholar is a free academic search engine, but also reaches out to more than 3 million papers published across 42,500 journals or more than 180 million papers from all fields of science. The Semantic Scholar repository is partnering with many trustable digital library providers such as IEEE, Microsoft Academic, Springer Nature, SAGE, Taylor and Francis Group, ACM. Thus, we believe the use of Semantic Scholar is reliable enough to represent most publications and reduce the problem of likely redundancy issues in the search results.

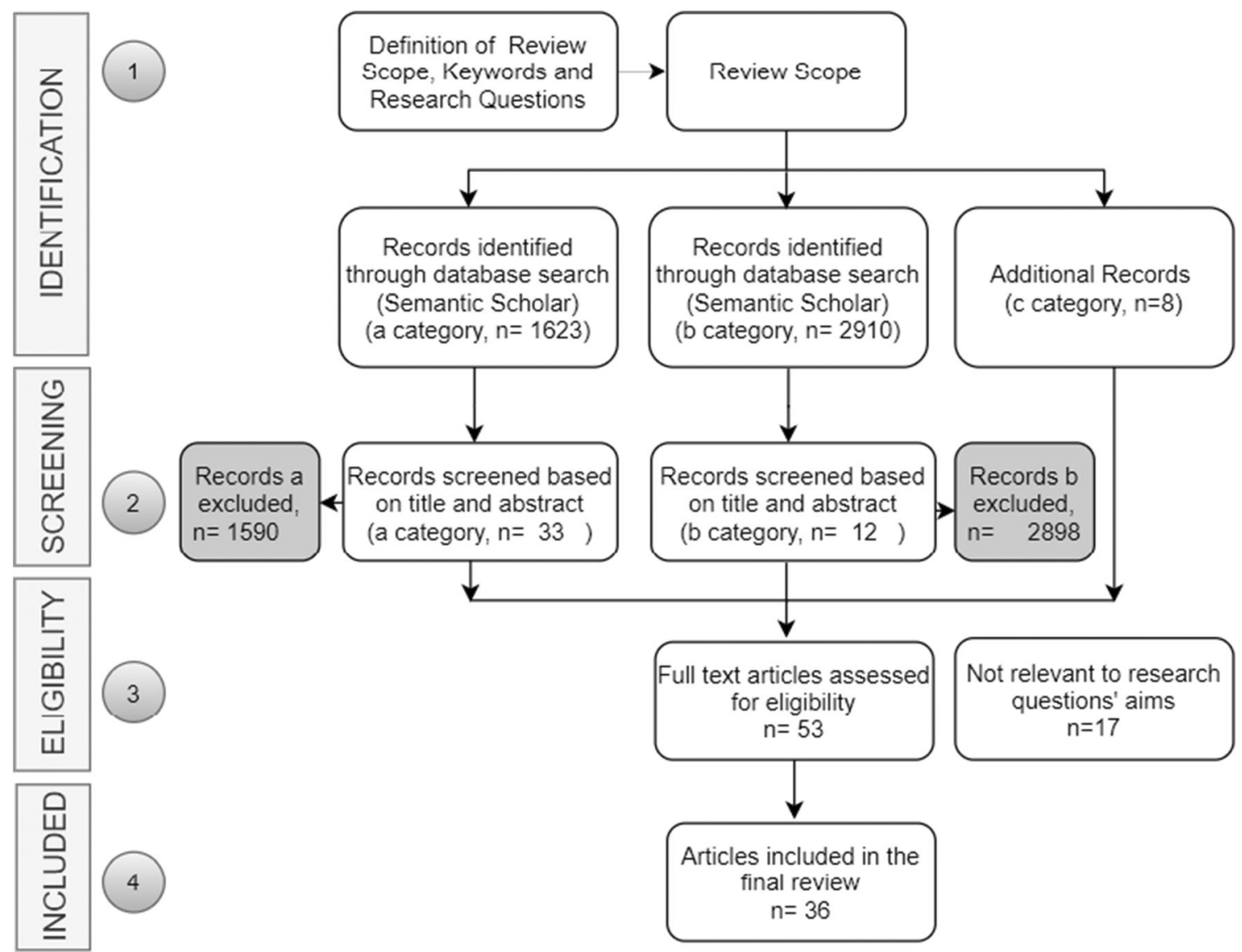

Fig. 1 Prisma process for systematic literature review 
The search was conducted in two rounds. Part A of the search was conducted during 4-5 February 2018, and part B was conducted on 22. March 2020. Using the search phrase ("Universal Design" OR "Design for all" OR Accessibility) AND ("Crisis Management" OR "Emergency Management" OR "Disaster Management" OR "Disaster Resilience") AND (ICT OR Web* OR Technology OR Digital OR Mobile OR Smartphone OR Computer OR Internet), the search resulted in 1623 papers for 2008-2018 and 2910 for 2018-2020.

Second, the Screening step. In these two rounds of review processes, the papers were manually checked against the predefined inclusion and exclusion criteria. In the first iteration, the title and abstract were checked first, and if the title and abstract do not give enough information for making a decision, the full text was briefly checked. After this iteration, we concluded with a preliminary selection of 33 papers in part $\mathrm{A}$, and 12 papers in part B. All authors involved in the review process would validate the screening process conducted by others and reach an agreement on papers that will go to the next stage of the review process. In this screening process, we have excluded 1590 papers in A category and 2896 papers in B category.

Third, the Eligibility step. Apparently, our in-depth review showed that some papers still were not relevant or not at all fulfilled our criteria, and therefore, would not be suitable for further analysis. Some papers used the accessibility term, but in fact, it was about access to information, access to resources or access to the Internet. In other words, in some cases accessibility was to be interpreted as "availability" or "being able to reach or obtain" rather than about the design of a system or a technology that could be used by all regardless of any impairments. Some papers discussed accessibility and Universal Design in terms of evacuation routes and built environment. Therefore, we discarded 10 papers from part A and 7 from part B from being included in the results and analysis. In other words, 17 papers were excluded from further analysis.

This left us with 23 papers in part A and 5 papers in part B. In addition, we included part $C$ with a selection of 8 known papers that were not found in the initial search. The additional papers that are not derived from the systematic review, are also known in the PRISMA method. In our chart in Fig. 1, is shown in the additional box on the right side of the eligible papers, in the Eligibility stage (third step).

Fourth, the Inclusion step. All authors read through the papers that were ready for the coding process, based on the predefined framework. As outlined in Section 2, we use a four-part framework to analyse the relevant papers. First, we categorize the work based on stakeholders involved. Second, according to ICT tools category for Emergency Management as suggested by Aman et al. (2012). Third, we examine the degree of Universal Design focus expressed in the paper. Fourth, we determine if the approach is about evaluating existing systems, prototyping, model or design or proposal of a system, case study, or about testing such as automated, heuristic and user tests.

Thus, in the following we present the analysis of a total of 36 papers from parts $\mathrm{A}, \mathrm{B}$ and $\mathrm{C}$.

\section{Literature Review: Overview and Results}

\subsection{Overview of the Final Selection of Papers}

As mentioned earlier, after the final thorough filtering, we ended up with a final selection of 36 papers. Figure 2 shows the number of papers from each year since 2009 . We notice that there are two peaks, one in 2014 with 7 papers and 8 papers in 2019 . However, there may still be more papers published in 2020.

Moreover, the main topics covered by the selected publications can be classified as the list seen in Table 1 (see Table 2 for references).

\subsection{Stakeholders}

Figure 3a shows the distribution of the different stakeholders that the different papers focus on. Note that more than one stakeholder can be covered in one paper. We notice that there is an overwhelming focus on the public (38\%, or 25 out of 65 occurrences), compared to other stakeholders such as Government agencies (14\% or 9 out of 65 occurrences), Volunteers (12\% or 8 out of 65 occurrences), first Responders and Decision makers (11\% or 7 out of 65 occurrences in each category). While Experts and NGO are 5\% (3 out of 65 occurrences) and 3\% (2 out of 65 occurrences) respectively. The examples of articles that purely address the public as a target audience are A22 (Hosono et al. 2014), A23 (Onorati et al. 2014), A24 (Easton 2014), A30 (Ito et al. 2013), A33 (Malizia et al. 2010), C1 (Radianti et al. 2017) and C5 (Tunold et al. 2019). The technologies intended for the public often typically are intended for communication, warning, evacuation and navigation. Note that the number of

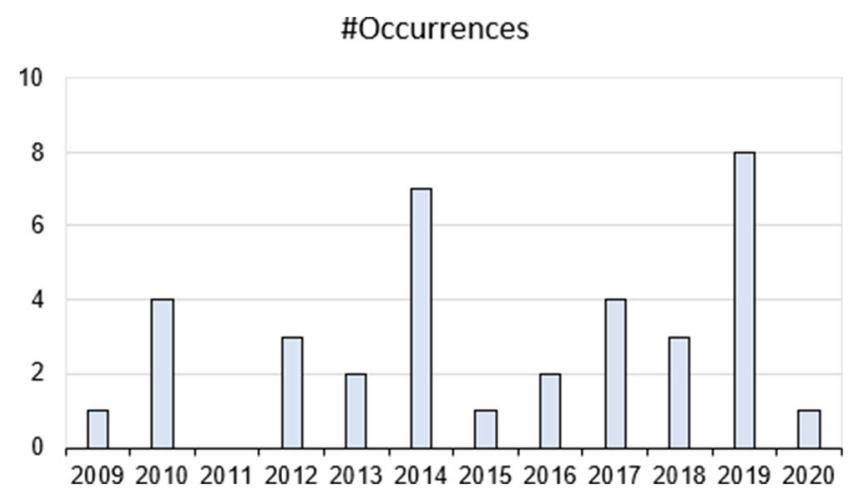

Fig. 2 Publications per year between 2009-2020 on Universal Design of ICT in Emergency Management 
Table 1 Topics coverage

\begin{tabular}{ll}
\hline Topics & Article ID \\
\hline Online Social Network; Web 2.0; Social Media & A1, A27, A32, \\
Open Source Intelligence; Simulations, e-Service & A21, \\
Systematic Training, Teaching & A7, A18, \\
Technology Mediated Citizen Participation; Disaster Resilience; Community & A5, A8, A11, A13, A19, B5, C7 \\
$\quad$ Resilience; User Engagement, Community-Centred Crisis System, Inclusion, & \\
Digital Divide, Social Vulnerability & A10, \\
Ainguistic, Multilingualism & A12, A14, A16, A23, A30, A33, \\
Sccessible technology, Assistive Technology, Alert Technology, Communication Technology & A19, A22, A31 \\
Usability, User Interface, User Testing, Universal Design & A20, A28, B7, B10, C1, C2, C3, C5, C6 \\
Volunteers & B9, B12, C4 \\
Policy & A24, C8
\end{tabular}

occurrences are higher than the amount of the articles, because we found one article that touches upon more than one stakeholders.

\subsection{Tool Categories}

Figure $3 b$ ) shows the distribution of different tool categories covered in the selected papers. We observe that Communication is highly important among the tool categories being discussed and analysed in the selected papers, made up slightly more than a half of the articles $(51 \%)$.

\subsection{Degree of Universal Design}

Figure 4a shows the degree of Universal Design (UD) focus among the papers. Although the biggest group was papers with $U D$ as the main topic (31\%, or 11 out of 36 papers), we see that there were numerous papers in each of the categories where the distribution was only slightly different. The paper with the Explicit UD category was $28 \%$, or 10 out of 36 papers. While the articles categorized as the Implicit UD and Brief Mention UD were $22 \%$ and $19 \%$ respectively.

\subsection{Methods Used}

Figure $4 \mathrm{~b}$ shows the distribution of methods used in the selected papers. We see that although there are many proposals and prototypes, the lower numbers for field trials and user testing may indicate that much of the research is not yet reflected in publicly available products. Another observation is that although Human-centred design is an essential approach to Universal Design, few papers explicitly mention this.

\subsection{Overview of Articles}

Table 2 shows a complete overview of the articles tagged as A1-A33, B5-B12 and C1-C8 evaluated across the different criteria described in the framework in Sect. 2 (the gaps in the numbering of the article labels are caused by the discarded articles). In the following, we will further look into the different aspects of our analysis framework.

\section{Key Findings and Gaps}

Through literature analysis, we have identified research gaps related to universal design in EM. Some of the gaps are in accordance with the gaps identified in Gjøsæter et al. (2018). For these gaps, we have updated their status based on whether they have been / are being addressed. Furthermore, we have identified some additional gaps that are not included in Gjøsæter et al. (2018).

\subsection{Revisiting Gaps Identified in Gjøsæter et al. (2018)}

We found that there is an increase in recent research addressing some gaps identified in Gjøsæter et al. (2018). For example, the gaps in Gjøsæter et al. (2018) related to awareness about people with disabilities and about how universal design can benefit all users in Emergency Management are gradually closing. This is demonstrated in the B and $\mathrm{C}$ papers in our analysis and particularly B10 (Gjøsæter et al. 2019). In addition, we have found more recent efforts focusing on addressing the gap about mobile systems being not considering universal design. Such efforts include for example B7 (Nass et al. 2018), B10 (Gjøsæter et al. 2019) and B12 (Gerstmann et al. 2019). 


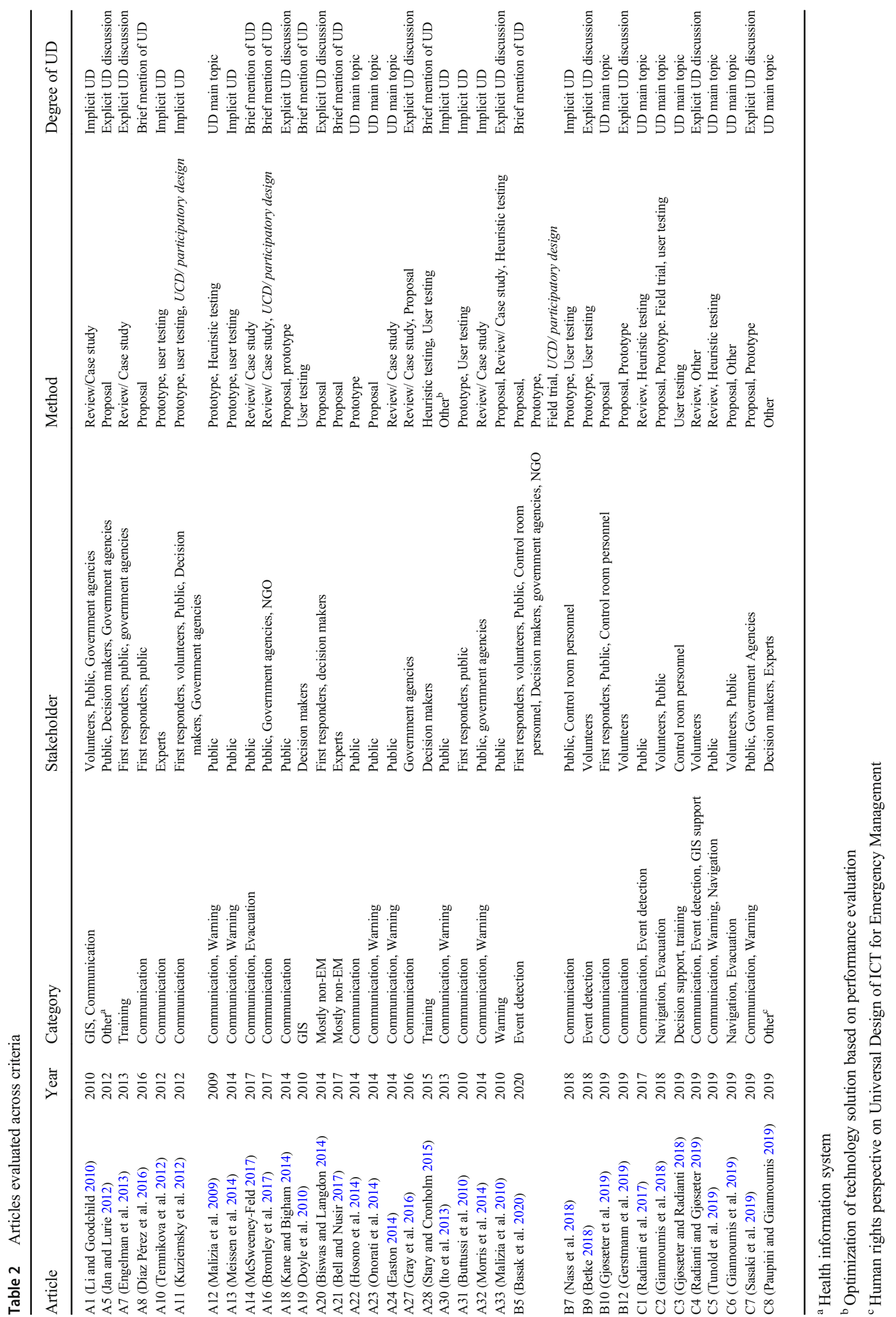




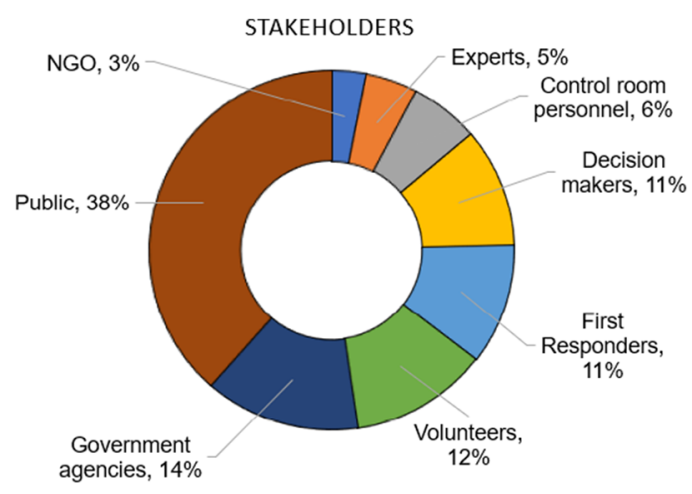

Fig. 3 a Distribution of stakeholders; $\mathbf{b}$ Distribution of tool categories

However, our analysis also shows that several of the findings and gaps identified in Gjøsæter et al. (2018) remain relevant. For example,

- Most of the work on ICT tools and platforms for Emergency Management does not take into account Universal Design nor accessibility.

- There is a lack of communication support between emergency medical responders and people that are deaf.

- In use of social networks in emergency situations, the age gap was identified as significantly more severe than the disability gap.

- Good efforts towards accessible tools and platforms exist, but most of them are on the conceptual or at best on the prototype level.

- Research on the use of assistive technology by older adults during disasters is a neglected issue.

- Accessibility is often limited to access to Internet, rather than concerning the diversity of stakeholders and their access to digital solutions in Emergency Management.

\subsection{Additional Gaps Identified}

From our systematic review, and also from comparing with the papers that were not included as relevant in the study, we found several new key gaps. For example:

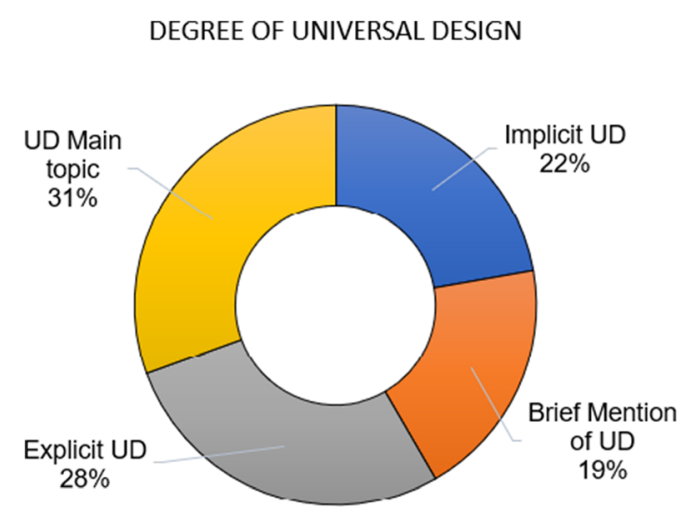

Fig. 4 a Distribution of degree of UD focus; $\mathbf{b}$ Distribution of methods used

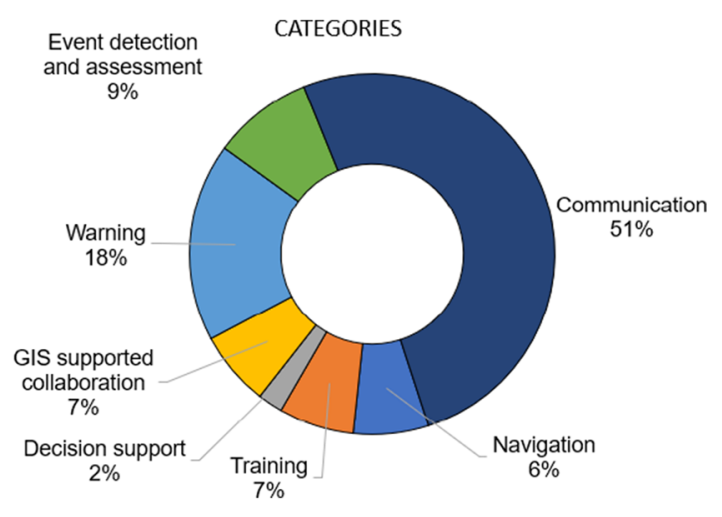

- While the number of new papers focusing on Universal Design of ICT for Emergency Management is on the rise, there are still few papers on Emergency Management tools that fully embrace Universal Design.

- There are still few Emergency Management tools and platform development processes that use Human Centred Design.

- Emergency Management tools that discuss Universal Design or Accessibility are in general focused on the general public, although recent research on situational disabilities in disasters, including B10 (Gjøsæter et al. 2019, 2020), indicate that all stakeholders in a disaster may benefit from Universal Design.

- There is an increasing focus on Digital Volunteers, where communication tools would in particular benefit from Universal- and Human-Centered Design.

- Maps for visualising disasters tend not to be accessible, see for example C5 (Tunold et al. 2019).

\section{Discussion and Future Directions}

In this section, we will first revisit the discussion of the potential impact of the different categories of tools on various stakeholders based on an analysis of information flow from

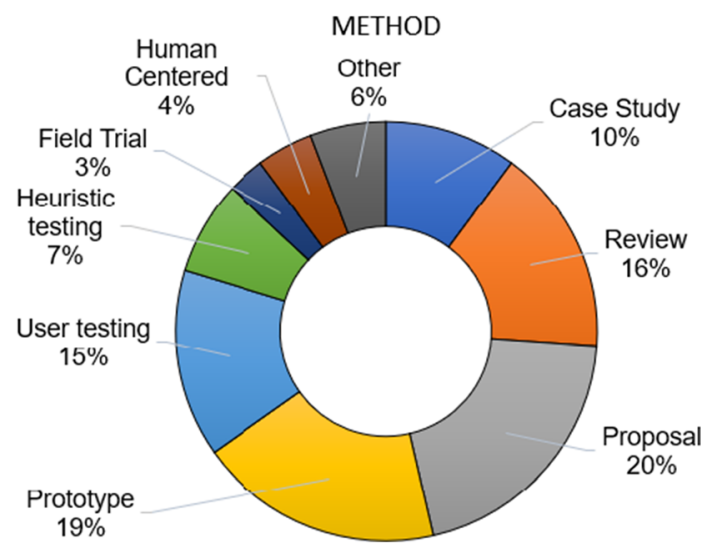


Gjøsæter et al. (2018), and give it an update based on how the different categories of Emergency Management ICT tools and platforms in relation with different stakeholders has been covered in research in terms of Universal Design as found in Table 2. Combined with the updated overview of gaps in Section 5, this will form a foundation for a revised research agenda.

\subsection{Discussion on Prioritization of Gaps}

In (Gjøsæter et al. 2018), we prioritize the importance of Universal Design in different classes of ICT tools in Emergency Management according to the following issues:

- How many people would be affected by a lack of access?

- How severely are they affected?

At that time, we prioritised the information flows as follows:

1 Information between the public and emergency practitioners. (PEP)

2 Information crowdsourcing concerning emergency situations. (CR)

3 Information among first responders. (FR)

4 Information among the public concerning less-urgent issues such as finding friends and family. (PFF)

5 Information flow among practitioners. E.g. in control rooms and decision makers' offices. (PRR)

6 Non-essential information flow, training, etc. (NIF)

The logic of the prioritisation is as follows: In the first two classes of tools (PEP and CR), we can expect that members of the public are actively avoiding hazards in the affected area, and in addition to any disabilities they will be affected by situational disabilities such as reduced ability to interact, type and read on a mobile terminal because of the situation that may involve severe weather, noise, crowds, etc. This, combined with the importance of the communication, made these cases top priority. Concerning the third class of tools (FR), the responders are affected by the same issues, but are trained to come with them and have specialized communication equipment. Additionally, we should also not neglect the importance of Universal Design and usability for communication among practitioners (PRR). Although they are in a controlled environment and trained with the communication and information equipment, the amount of information that needs to be processed makes them prone to be affected by situational disabilities as well as the demons of situational awareness (Gjøsæter et al. 2019, 2020; Endsley et al. 2003). It is therefore important that their interaction with the equipment is as smooth as possible.

\subsection{Stakeholder Perspective on Prioritization of Gaps}

Figure 5 shows a 3D bar chart of the combinations of stakeholders and categories. Here it becomes clear that the Public is the group of stakeholders that have received the most attention in the research with 19 papers, In recent articles found in the second round of review, Volunteers have also come up as a group that has got significant attention with 8 papers. Communication with Government Agencies is also a noteworthy topic with 6 papers. This is in line with our recommendations from Gjøsæter et al. (2018), as these groups of stakeholders are where we considered the impact to be biggest, and in particular with relation to tools for communication and warning. Communication among first responders is also a reasonably popular topic.

\subsection{Future Research Directions}

Based on the discussion above and the identified gaps, we suggest the following future research directions:

\subsubsection{Diverse Stakeholders and Abilities}

As we are becoming increasingly aware, first responders, control room personnel and decision makers are also affected to various degrees by situational disabilities and the so-called demons of situational awareness (Gjøsæter et al. 2019, 2020; Endsley et al. 2003). The effects of this should therefore be put under particular focus in the future, to ensure that they are properly understood and mitigated.

As the age gap can be even more severe than the disability gap, it is important to perform research on the types of disabilities, situational disabilities, assistive- and welfare technologies and other characteristics that are typical of the aging population, and how they respond to and are affected by emergency situations, so this can be taken into account in the Universal Design of tools and platforms for Emergency Management.

\subsubsection{Methodological Issues for Design and Development}

Although there is still a need to raise awareness through targeted information to relevant stakeholders with an emphasis on relevant laws and regulations, and consequences of failing to comply with Universal Design, the situation is improving, based on the increasing number of papers. However, it is not only about the will to produce universally designed solutions, but also about knowing how to do so. It is clear that there is a lack of knowledge of suitable development methods to achieve Universal Design, highlighted in this study through the lack of findings on Human-Centred Design and explicit focus on Universal Design. Clear Universal Design-related recommendations and requirements for new acquisitions of 
Fig. 5 Stakeholders vs. tool categories
Tool Categories vs. Stakeholders

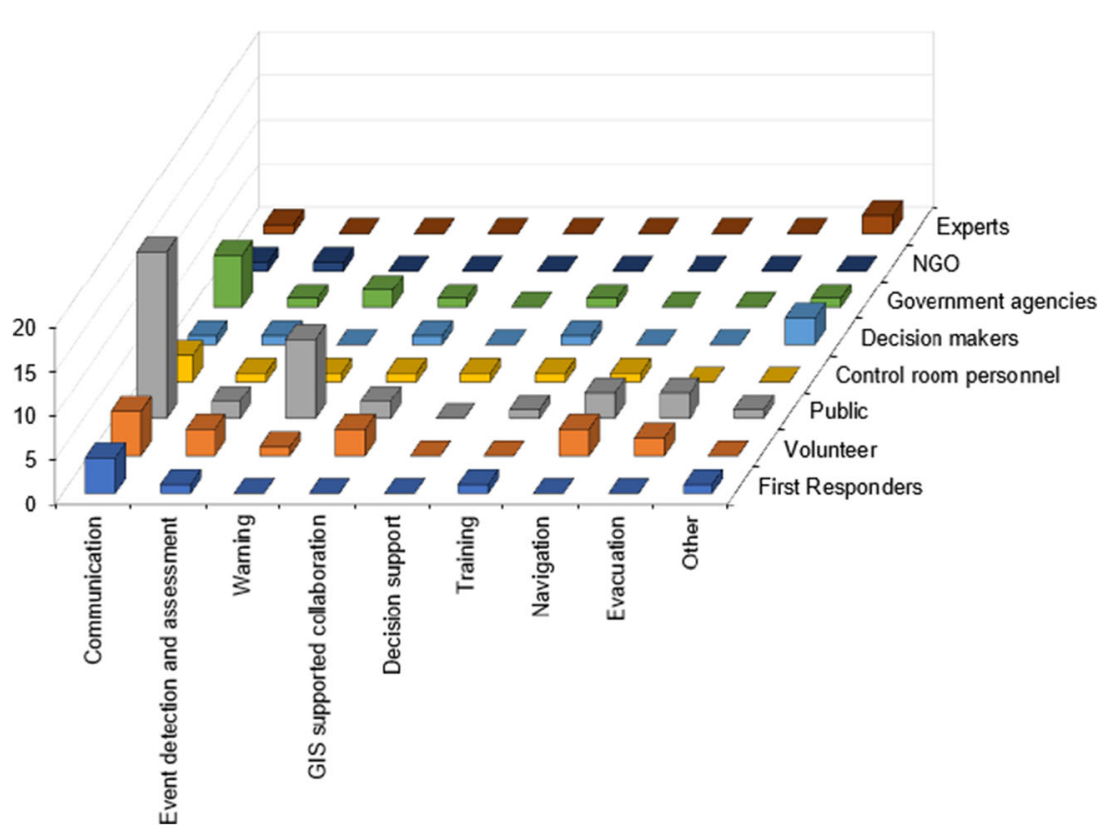

digital solutions should be provided, based on HumanCentred Design. User involvement with a broad diversity of users in all stages of development of new systems, including design and testing, is essential, and must be strongly encouraged. This is where the impact of this emerging research field might be most clearly seen in the future. We therefore see a clear need for developing a HCD-based development process model for ICT for Emergency Management.

A standardized framework for accessibility testing and evaluation of tools and technologies for Emergency Management would be very beneficial, as it would simplify the identification of barriers. A selection of relevant and popular tools and platforms for each of these prioritized categories should be evaluated, in order to identify common barriers to create barrier removal strategies and facilitate Universal Design of the next generation of tools.

\subsubsection{Tools/technologies in Emergency Management}

Based on the findings above, like we also concluded in 2018 (Gjøsæter et al. 2018), Warning systems should still have a very high priority in terms of potential impact. We have seen several research efforts in this area, e.g. (Sasaki et al. 2019), but there is still a way to go towards fully implemented universally designed warning systems that functions well for all users including people with hearing-related disabilities.

Although Information sharing and crowdsourcing tools has become a hot topic recently, the importance of these is also increasing as people are more and more using mobile tools for communication. These tools are therefore still number two on our Research Agenda increasingly important in disaster resilience, and it is essential that these tools are accessible and usable for as many potential users as possible, both from the general public and active volunteers (Radianti et al. 2017; Radianti and Gjøsæter 2019). This should have a high priority as these tools are affecting many users and their ability to report the situation in their area. Situational disabilities such as being unable to type messages on a mobile phone using virtual keyboard due to cold, wet and shaky hands, noisy background, only using one hand, bumpy roads, eyes are busy observing surrounding areas, can frequently occur in a disaster situation, adding to the importance of the universally designed information sharing tools.

We still expect to see the increasing use of wireless technologies to empower people with disabilities regarding individual preparedness (technology outreach), response (warning and reaction), recovery (enable location of accessible shelters) and mitigation (wireless technologies integrated into postdisaster reconstruction).

Universally designed situation maps for the public, volunteers and control room personnel, would be of great value.

Emerging Technologies like augmented reality can become essential. However, they may bring a new range of potential barriers and solutions to the table., e.g. in evacuation situations;

Assistive technologies facilitating communication between responders and victims can be of great value.

Although Universal Design of ICT for interactions with the public and volunteers should be highly prioritized, there are 
still many other important issues such as Universal Design of communication tools and ICT equipment for control rooms, situation visualization tools, decision support systems, logistics systems, etc.

\section{Limitations and Conclusions}

Given the continuing number of man-made and natural disasters around the world, the development of accessible technologies is clearly very important and has a high potential impact in terms of helping people affected by these disasters. We have conducted a systematic literature review of research on Universal Design and accessibility of ICT tools and technologies for Emergency Management published in years 20082020 focusing on stakeholders' perspective and identified gaps as well as trends in this emerging research area. We have found that although awareness about people with disabilities is increasing in EM, still few tools in EM fully embrace Universal Design. Existing research in this area focus mainly on general public and very few on other stakeholders such as first responders, control room personnel and decision makers. Promising research trends identified include digital volunteers (Radianti and Gjøsæter 2019; Gerstmann et al. 2019; Betke 2018) and situational disabilities and situation awareness (Gjøsæter et al. 2019).

We have also highlighted and prioritized the most important research activities needed to bridge the gaps. Research in EM should cover diversity of stakeholders who can be affected by both age-related conditions and situational disabilities. Human-centred design approach should be adopted in design and developed of tools for EM to ensure the needs of diverse stakeholders are taken into consideration. It is our hope that in the future, Universal Design will be an obvious and obligatory feature of any Emergency Management system. Until then, this research agenda may provide some steps along the way towards that goal.

Some limitations of this study should be mentioned. A stronger theoretical foundation related to universal design or emergency management could be adopted to guide the literature analysis. For example, the seven Universal Design principles $^{3}$ could help to provide a more detailed analysis of the tools in EM. In addition, a more careful selection of search terms avoiding the frequently ambiguously used term accessibility, might have contributed to far less false positives to handle in the manual filtering. On the other hand, removing the term may also give false negative results thus run the risk of missing important research where this is the only term used for the efforts to make ICT tools for Emergency Management accessible and usable for all users. Use of the term

\footnotetext{
3 https://projects.ncsu.edu/ncsu/design/cud/about_ud/udprinciplestext.htm.
}

accessibility without explicit reference to Universal Design is particularly common in the Brief Mention of UD category.

Funding Open Access funding provided by University of Agder.

Open Access This article is licensed under a Creative Commons Attribution 4.0 International License, which permits use, sharing, adaptation, distribution and reproduction in any medium or format, as long as you give appropriate credit to the original author(s) and the source, provide a link to the Creative Commons licence, and indicate if changes were made. The images or other third party material in this article are included in the article's Creative Commons licence, unless indicated otherwise in a credit line to the material. If material is not included in the article's Creative Commons licence and your intended use is not permitted by statutory regulation or exceeds the permitted use, you will need to obtain permission directly from the copyright holder. To view a copy of this licence, visit http://creativecommons.org/licenses/by/4.0/.

\section{References}

Aman, H., Irani, P., \& Liang, H.-N. (2012). A review of information communication technology applied on common tasks during times of emergency. Paper presented at the 9th International ISCRAM Conference (ISCRAM2012).

Basak, J., Bhaumik, P., Roy, S., \& Bandyopadhyay, S. A. (2020) Crowdsourcing based Information System Framework for Coordinated Disaster Management and Building Community Resilience. In Proceedings of the 21st International Conference on Distributed Computing and Networking (pp. 1-6).

Bell, D., \& Nusir, M. (2017) Co-design for Government Service Stakeholders. In Proceedings of the 50th Hawaii International Conference on System Sciences.

Bennett, D., Phillips, B. D., \& Davis, E. (2017). The future of accessibility in disaster conditions: How wireless technologies will transform the life cycle of emergency management. Futures, 87, 122-132.

Betke, H. A. (2018) Volunteer coordination system approach for crisis committees. In ISCRAM.

Biswas, P., \& Langdon, P. (2014) User interface design for developing countries. In, 2014 (pp. 1-5). Piscataway: IEEE.

Bromley, E., Eisenman, D. P., Magana, A., Williams, M., Kim, B., McCreary, M., et al. (2017). How do communities use a participatory public health approach to build resilience? The Los Angeles county community disaster resilience project. International Journal of Environmental Research and Public Health, 14(10), 1267.

Buttussi, F., Chittaro, L., Carchietti, E., \& Coppo, M. (2010) Using mobile devices to support communication between emergency medical responders and deaf people. In Proceedings of the 12th international conference on Human computer interaction with mobile devices and services (pp. 7-16): New York: ACM.

Díaz, P., Carroll, J. M., \& Aedo, I. (2016). Coproduction as an approach to technology-mediated citizen participation in emergency management. Future Internet, 8(3). https://doi.org/10.3390/fi8030041.

Doyle, J., Bertolotto, M., \& Wilson, D. (2010). Evaluating the benefits of multimodal interface design for CoMPASS - a mobile GIS. GeoInformatica, 14(2), 135-162.

Easton, C. (2014). The digital divide, inclusion and access for disabled people in IT supported emergency response systems: A UK and EUbased analysis. In ISCRAM.

Endsley, M., Bolté, B., \& Jones, D. (2003). SA demons: The enemies of situation awareness. Designing for Situation Awareness: An Approach to User-Centered Design (pp. 31-42). London: Taylor \& Francis. 
Engelman, A., Ivey, S. L., Tseng, W., Dahrouge, D., Brune, J., \& Neuhauser, L. (2013). Responding to the deaf in disasters: establishing the need for systematic training for state-level emergency management agencies and community organizations. BMC Health Services Research, 13(1), 84.

Gerstmann, S., Bethke, H., \& Sackmann, S. (2019). Towards Automated Individual Communication for Coordination of Spontaneous Volunteers. Proceedings of the Information Systems for Crisis Response and Management (ISCRAM).

Giannoumis, G. A., Ferati, M., Pandya, U., Krivonos, D., \& Pey, T. (2018). Usability of indoor network navigation solutions for persons with visual impairments. In Cambridge Workshop on Universal Access and Assistive Technology (pp. 135-145). Berlin: Springer.

Giannoumis, G. A., Gjøsæter, T., Radianti, J., J., \& Paupini, C. (2019). Universally Designed Beacon-Assisted Indoor Navigation for Emergency Evacuations. Paper presented at the Third IFIP Conference on Information Technology in Disaster Risk Reduction Poznan, Poland.

Gjøsæter, T., \& Radianti, J. (2018). Evaluating accessibility and usability of an experimental situational awareness room. In AHFE2018, Advances in Design for Inclusion (pp. 216-228). Berlin: Springer International Publishing.

Gjøsæter, T., Radianti, J., \& Chen, W. (2018). Universal design of ICT for emergency management - A systematic literature review and research agenda. In International Conference on Universal Access in Human-Computer Interaction, Las Vegas, USA, 2018 (pp. 63-74, Universal Access in Human-Computer Interaction. Methods, Technologies, and Users). Berlin: Springer International Publishing.

Gjøsæter, T., Radianti, J., \& Chen, W. (2019). Understanding Situational Disabilities and Situational Awareness in Disasters. Paper presented at the 16th International Conference on Information Systems for Crisis Response and Management (ISCRAM 2019).

Gjøsæter, T., Radianti, J., \& Chen, W. (2020). Towards Situational Disability-aware Universally Designed Information Support Systems for Enhanced Situational Awareness. Paper presented at the 17th International Conference on Information Systems for Crisis Response and Management (ISCRAM 2020) (in press).

Gray, B., Weal, M., \& Martin, D. (2016). Social media and disasters: a new conceptual framework. Proceedings of the ISCRAM 2016 Conference, Brazil (p. 6)

Hosono, N., Inoue, H., Nakanishi, M., \& Tomita, Y. (2014). Urgent mobile tool for hearing impaired, language dysfunction and foreigners at emergency situation. In Proceedings of the 16th international conference on Human-computer interaction with mobile devices \& services (pp. 413-416). New York: ACM.

ISO (2019). ISO 9241 - 210:2019(en) Ergonomics of human-system interaction - Part 210: Human-centred design for interactive systems. Geneva: ISO.

Ito, A., Yabe, T., Tsunoda, K., Ueda, K., Ifukube, T., Fujii, M., et al. (2013). A study of optimization of IDDD (Information Delivery System for Deaf People in a Major Disaster). In Computing and Networking (CANDAR), 2013 First International Symposium on (pp. 422-428). Piscataway: IEEE.

Jan, S., \& Lurie, N. (2012). Disaster resilience and people with functional needs. New England Journal of Medicine, 367(24), 2272-2273.

Kane, S. K., \& Bigham, J. P. (2014). Tracking@ stemxcomet: teaching programming to blind students via $3 \mathrm{D}$ printing, crisis management, and twitter. In Proceedings of the 45th ACM technical symposium on Computer science education (pp. 247-252). New York: ACM.

Kuziemsky, C. E., O'Sullivan, T. L., \& Corneil, W. (2012). An upstreamdownstream approach for disaster management information systems design. In Proceedings of the ISCRAM Conference.
Li, L., \& Goodchild, M. F. (2010). The role of social networks in emergency management: A Research Agenda. International Journal of Information Systems for Crisis Response and Management (IJISCRAM), 2(4), 48-58.

Malizia, A., Acuña, P., Onorati, T., Díaz, P., \& Aedo, I. (2009). CAPONES: an emergency notification system for all. International Journal of Emergency Management, 6(3-4), 302-316.

Malizia, A., Onorati, T., Diaz, P., Aedo, I., \& Astorga-Paliza, F. (2010). SEMA4A: An ontology for emergency notification systems accessibility. Expert Systems with Applications, 37(4), 3380-3391.

McSweeney-Feld, M. H. (2017). Assistive technology and older adults in disasters: implications for emergency management. Disaster Medicine and Public Health Preparedness, 11(1), 135-139.

Meissen, U., Hardt, M., \& Voisard, A. (2014). Towards a general system design for community-centered crisis and emergency warning systems. In ISCRAM.

Morris, J. T., Mueller, J. L., \& Jones, M. L. (2014). Use of social media during public emergencies by people with disabilities. Western Journal of Emergency Medicine, 15(5), 567.

Nass, C., Jung, J., Groen, E. C., Villela, K., \& Holl, K. (2018). Interaction modes for emergency mobile apps. Mobile Information Systems: 3437957. https://doi.org/10.1155/2018/3437957.

Onorati, T., Malizia, A., Díaz, P., \& Aedo, I. (2014). Modeling an ontology on accessible evacuation routes for emergencies. Expert Systems with Applications, 41(16), 7124-7134.

Panic, N., Leoncini, E., de Belvis, G., Ricciardi, W., \& Boccia, S. (2013). Evaluation of the endorsement of the preferred reporting Items for systematic reviews and meta-analysis (PRISMA) statement on the quality of published systematic review and meta-analyses. PLOS ONE 8(12). https://doi.org/10.1371/journal.pone.0083138.

Paupini, C., \& Giannoumis, G. A. (2019). Applying universal design principles in emergency situations. In International Conference on Human-Computer Interaction (pp. 511-522). Berlin: Springer.

Radianti, J., \& Gjøsæter, T. (2019). Digital volunteers in disaster response: accessibility challenges. In International Conference on Human-Computer Interaction (pp. 523-537). Berlin: Springer.

Radianti, J., Gjøsæter, T., \& Chen, W. (2017). Universal design of information sharing tools for disaster risk reduction. In Second IFIP Conference on Information Technology in Disaster Risk Reduction, Sofia-Bulgaria.

Sasaki, J., Maejima, T., Li, S., Sato, Y., Hiyama, M., \& Herrera-Viedma, E. (2019). Life-Area Broadcasting System (LABS) for Normal and Emergency Cases by Using Easy Contents Management System and New Speaker Devices. Paper presented at the ISCRAM 2019.

Stary, C., \& Cronholm, S. (2015). Method transfer across domains and disciplines: enriching universal access development. Berlin: Springer.

Temnikova, I. P., Orasan, C., \& Mitkov, R. (2012). CLCM-A Linguistic resource for effective simplification of instructions in the crisis management domain and its evaluations. In LREC (pp. 3007-3014).

Tunold, S., Radianti, J., Gjøsæter, T., \& Chen, W. (2019). Perceivability of Map Information for Disaster Situations for People with Low Vision. In International Conference on Human-Computer Interaction (pp. 342-352). Berlin: Springer.

Wentz, B., Lazar, J., Stein, M., Gbenro, O., Holandez, E., \& Ramsey, A. (2014). Danger, danger! Evaluating the accessibility of Web-based emergency alert sign-ups in the northeastern United States. Government Information Quarterly, 31(3), 488-497.

Publisher's Note Springer Nature remains neutral with regard to jurisdictional claims in published maps and institutional affiliations. 
Terje Gjøsæter is an associate professor at the Department of Information Systems at University of Agder, and an active member of the Centre for Integrated Emergency Management (CIEM) at UiA. He holds a secondary position as Associate Professor at Oslo Metropolitan University, and is a dedicated member of the research group for Universal Design of ICT. His main research interests include human-computer-interaction, universal design, usability and accessibility, and in particular universal design of ICT for emergency management and disaster resilience. In addition, he has a strong and active interest in diverse topics such as cyber-security, privacy, security in critical infrastructure, computer language theory, and metamodeling.

Jaziar Radianti ( $\mathrm{PhD}$ 2010), is an associate professor of Information Systems at the IS department and a researcher at the Center of Integrated Emergency Management of the University of Agder (Norway). Her research interests include system dynamics modeling, emergency management, security and privacy management, and disaster resilience. She has taken part in Smart Mature Resilience, Social Media Analytics for Society and Crisis Communication, and VR for Higher Education Erasmus+ European projects. She has published more than 80 scientific papers in conference proceedings as well as in journals such as Applied Artificial Intelligence, Engineering Application of Artificial Intelligence, International Journal for Information Systems for Crisis Management, and Computer and Education.

Weiqin Chen is Professor at department of computer science at Oslo Metropolitan University and leader of the research group for Universal Design of Information and Communication Technologies (UD-ICT). She has many years of teaching and research experiences in human computer interaction, assistive technology, and universal design of ICT. Her current research focuses on universal design for ICT in crisis and emergency management and ICT for people with disabilities. 